\title{
MASALAH DALAM DUNIA ISLAM
}

\author{
Eka Gunawan \\ Institut Ilmu Sosial Dan Ilmu Politik Yapis Biak \\ Email: eka01@gmail.com
}

\begin{abstract}
Abstrak
Studi ini menjelaskan pembenaran situasi dan bahkan keadaan yang harus dijelaskan oleh konsep masalah itu sendiri untuk memutuskan kemungkinan menghadapi masalah atau keadaan tersebut jika konsep tersebut diklaim dengan gagasan dan konsep yang setara tanpa mengetahui dan memahami. konsep. Pertama definisi, karakteristik, dan elemen konsep tentang apa masalah yang dimanifestasikan. Landasan teoritis dari perbedaan antara masalah dan apa yang diklaim / dianggap sebagai masalah dijelaskan. Persyaratan untuk definisi yang benar dan penentuan masalah serta persyaratan untuk menghilangkan masalah / masalah dari perspektif dunia, Islam dan Dunia Islam terwujud.

Kata kunci: Masalah, Islam, Sistem Internasional \& Dunia Islam
\end{abstract}

\begin{abstract}
This study explains the justification of situations and even circumstances that must be explained by the concept of the problem itself in order to decide the possibility of facing the problem or situation if the concept is claimed with equal ideas and concepts without knowing and understanding. concept. First the definition, characteristics, and conceptual elements of what the problem is to manifest. The theoretical underpinnings of the difference between the problem and what is claimed / considered to be the problem are explained. The requirements for the correct definition and determination of the problem as well as the requirements for eliminating the problem / problem from the perspective of the world, Islam and the Islamic world are realized. Keywords: Problems, Islam, International System \& the Islamic World
\end{abstract}

\section{A. PENDAHULUAN}

Masalah Dunia Islam adalah kendala yang menghalangi perlindungan keutuhan Dunia Islam atas nama pemahaman yang didasarkan pada penerimaan kesamaan tertentu dan kelanjutannya melalui pemantapan lebih lanjut. Fakta bahwa ada masalah

JURNAL PAPATUNG: Vol. 2 No. 1 Tahun 2019

ISSN: 2715-0186 
atau masalah karena dampak yang ditimbulkan memberi jalan pada hasil yang tidak diinginkan. Masalah / masalah / masalah adalah rujukan pada hasil yang tidak diinginkan yang akan ditimbulkan oleh konsekuensi serta kebutuhan untuk mempertahankan status / struktur kemunduran yang dikhawatirkan.

\section{B. PEMBAHASAN}

\section{Masalah dan Dunia Islam}

Ada elemen yang harus dibuktikan untuk mendefinisikan konsep "gangguan dalam sistem yang berfungsi" sebagai masalah. Ada empat elemen tersebut yaitu (i) waktu, (ii) manusia, (iii) proses / sistem / mekanisme dan (iv) informasi / berita. Waktu menjadi alasan beredarnya pembagian perbedaan dalam hal sebab dan akibat, bukan hanya untuk masalah. Waktu adalah kesempatan untuk menyelidiki apa yang kami sebut sebagai alasan dan untuk memahami penyebab dari suatu peristiwa. Karena sifatnya suatu peristiwa yang terjadi kemudian tidak dapat menjadi penyebab peristiwa sebelumnya. Akibatnya, keberadaan dan terjadinya suatu peristiwa dalam lingkaran sebab-akibat suatu fenomena, baik yang membawa ciri masalah maupun tidak, dimungkinkan dengan adanya waktu dan peluang yang diberikannya. Dengan kata lain, ada elemen untuk setiap masalah yang tidak bergantung pada sifat masalah, identifikasi dan penilaian solusinya. Kita dapat mengabaikan elemen ini dengan mengatakan bahwa waktu tersedia dan kita tidak dapat berbicara tentang ketiadaan waktu. Namun, menyadari keberadaan waktu, hubungan sebab-akibat dan kebutuhan yang ditimbulkan oleh hubungan ini memudahkan untuk memahami ranah keberadaan masalah serta batas-batas domain ini. Elemen kedua adalah elemen manusia. Ada masalah karena ada JURNAL PAPATUNG: Vol. 2 No. 1 Tahun 2019 ISSN: 2715-0186 
laki-laki. Sumber masalahnya adalah manusia. Selama jutaan tahun tidak ada masalah di dunia tanpa manusia. Peristiwa berikutnya tidak menimbulkan masalah dalam pengoperasian sistem. Namun, manusia adalah satu-satunya entitas yang dapat merusak fungsi sistem dan dengan demikian menyebabkan gangguan. Dapat dianggap bahwa manusia sudah ada dan karena alasan ini elemen ini juga dapat diabaikan. Alasannya karena ada elemen manusia untuk setiap masalah. Namun, menyadari bahwa masalah adalah kondisi manusia dan alasannya adalah manusiawi sangatlah penting dalam menentukan dan menyelesaikan masalah tersebut.

Elemen ketiga adalah elemen proses / mekanisme / sistem / struktur. Agar ada kegagalan dalam suatu proses, harus ada proses terlebih dahulu. Jika ada proses yang menurut kami tidak berfungsi, kami dapat mempelajari kerusakan ini dalam proses tersebut dan menyelesaikan serta menghilangkannya untuk mempertahankan pemrosesan. Dua elemen pertama sangat penting untuk sebuah masalah, namun, mereka bukanlah faktor penentu dalam definisi masalah tertentu. Agar menjadi masalah, harus ada struktur yang berfungsi dan gangguan yang terjadi pada berfungsinya struktur tersebut. Dalam hal ini, harus bisa diprediksi, karena fungsinya sudah terkenal. Artinya, harus diketahui bagaimana hal itu bisa terjadi / bisa terjadi, apakah bisa diatasi atau tidak dan bagaimana bisa diatasi jika bisa diperbaiki. Jika tidak, situasi yang terwujud seharusnya tidak didefinisikan sebagai masalah, tetapi sebagai kecelakaan. Sangat tidak mungkin untuk mengatakan bahwa struktur yang disebut "Dunia Islam" dan masalahnya yang disebutkan dan terlebih lagi, diagnosis yang benar dari masalahmasalah ini dan bahkan penyelesaian dan penghapusannya adalah struktur dengan pemrosesan. Tentu saja, ada negara dan geografi dengan Muslim atau orang yang JURNAL PAPATUNG: Vol. 2 No. 1 Tahun 2019 ISSN: 2715-0186 
mengaku sebagai Muslim. Namun demikian, tidak ada struktur yang disebut "Dunia Islam", yang memiliki proses / mekanisme khusus yang terdiri dari semua negara di mana orang-orang ini berada dan yang dapat memprediksi masalah karena diketahui operasi / mekanismenya. Oleh karena itu, kita tidak bisa membicarakan suatu masalah atau masalah yang dapat disebut / diidentifikasikan sebagai masalah / problem dari "Dunia Islam". Sebelum masalah, fungsinya harus ditentukan dan dimanifestasikan sedangkan fungsi seperti itu tidak ada. Mereka yang mengklaim bahwa "Dunia Islam" telah diberi nama dengan benar dan bahwa masalahnya adalah gangguan dalam operasi "Dunia Islam", dan dengan demikian mereka yang mengklaim bahwa ada elemen ketiga dari fungsi tersebut, atau ada orang yang menilai secara keliru apa yang menjadi masalah dan problematis serta ruang lingkup dan elemennya yang menjadi alasan kami melakukan penelitian ini. Oleh karena itu, mari kita evaluasi elemen lain seperti jika ada elemen ketiga. Unsur keempat adalah informasi / berita. Unsur terakhir ini merupakan unsur yang telah diperiksa karena secara umum diartikan sebagai masalah tanpa menelaah unsur lainnya. Namun, pemeriksaan ini telah dilakukan di eselon atas sejalan dengan definisi masalah yang dilakukan tanpa memperhatikan tentang mendefinisikan masalah dengan benar dan sampai ke dasar masalah. Selain itu, analisis pada eselon ini juga tidak memberikan hasil yang tepat bahkan pada level ini karena penanganan informasi mata pelajaran berbeda.

\section{Elemen Informasi dapat Dinilai di bawah Enam Judul:}

- Pengetahuan sistem / mekanik

- Mengetahui apakah sistem / mekanisme sudah benar atau belum

- Ketahuilah bahwa ada masalah / waspadai masalahnya JURNAL PAPATUNG: Vol. 2 No. 1 Tahun 2019 ISSN: 2715-0186 
- Mengetahui / dapat mendiagnosis apa yang menjadi masalah atau malfungsi

- Ketahui solusi dari masalah tersebut

- Tahu bagaimana mencapai solusi

Mengetahui struktur dan kemampuan untuk menentukan masalah yang mungkin timbul pada struktur ini membutuhkan pengetahuan yang kuat mengenai komponen dan elemen struktur serta masalah yang diartikan sebagai masalah. Akibatnya, informasi akan menjadi elemen utama yang memandu kita dan menentukan bagaimana kita berperilaku. Ketika subjeknya adalah Dunia Islam informasi ini akan memungkinkan penentuan masalah umat Islam serta solusinya, itu akan mencakup karakteristik Muslim, tentang Muslim serta karakteristik yang membedakan Muslim dan informasi tentang struktur yang disebut Islam. Dunia yang diyakini telah disusun dan dimiliki oleh umat Islam. Situasinya sama di eselon atas yang dibentuk oleh komunitas seperti pada skala individu dan masyarakat yang terdiri dari individu. Informasi akan menentukan struktur yang dibangun dan apakah struktur tersebut akan dipertahankan atau tidak serta menentukan masalah yang mungkin timbul beserta solusinya. Karena struktur yang kita bahas dalam studi ini adalah Dunia Islam dan eselon atas Dunia Islam terdiri dari eselon atas Muslim di lebih dari satu negara (tentu saja negara-bangsa), pertamatama perlu dinilai asosiasi negara bagian dan informasi. Dengan sistem pendidikan wajib yang diberlakukan oleh negara-bangsa, individu dan, pada akhirnya, masyarakat terdidik dan menjadi berpengetahuan. Jenis pembelajaran yang akan dijalani orang yang akan dididik akan ditentukan oleh jawaban tentang apa yang diterima secara universal dan berdasarkan nilai-nilai kontemporer. Jawaban ini juga akan sama untuk mengajar. JURNAL PAPATUNG: Vol. 2 No. 1 Tahun 2019 ISSN: 2715-0186 
Entah Anda akan memberikan pendidikan yang diatur berdasarkan nilai-nilai Anda sendiri dan ketinggalan zaman dan reaksioner, atau Anda melanjutkan ke arah dunia lain dengan memberikan pendidikan yang didasarkan pada penerimaan / kepercayaan pada yang benar dan yang salah dan menjadi kontemporer. Akibatnya, Anda akan menjadi kontemporer dan "penipu" Anda akan menjadi penentu kontemporer, bukan era / tempus (waktu). Orang-orang yang pernah dididik / dididik menurut aturan-aturan yang didasarkan pada budaya mereka sendiri dan dididik / dididik menurut aturanaturan ini selama ratusan tahun kini dididik / dididik menurut para penguasa kontemporer. Semua aspek di bidang pendidikan / pengajaran akan ditentukan menurut aturan kontemporer dari kebiasaan makanan dan minuman hingga tata cara pernikahan, dari hubungan dewasa-di bawah umur hingga hubungan keluarga, dari tata cara kehidupan profesional dengan penentuan prioritas dalam hidup. Faktanya, aturan dan informasi kontemporer ini akan menentukan apa yang perlu ditargetkan oleh negara dan apa yang harus dilakukan sejalan dengan target tersebut daripada apa yang harus ditargetkan oleh individu dan masyarakat. Meskipun wajib belajar-belajar yang diamanatkan menjadi negara-bangsa tampaknya memberikan kesempatan untuk mengadopsi nilai-nilai negara dan bangsa, itu memastikan pengajaran pengetahuan dengan seluruh dunia yang telah dihasilkan di pusat tunggal yang ia lebih didasarkan pada daripada nilai-nilai negara dan bangsa yang relevan. Konsekuensi dari penyampaian pengetahuan yang sama selaras dengan seluruh dunia dimanifestasikan sebagai berikut:

- Pertama, diagnosis masalah yang termanifestasi serta menemukan solusi untuk masalah ini akan didasarkan pengetahuan ini. Namun, pencarian sumber masalah JURNAL PAPATUNG: Vol. 2 No. 1 Tahun 2019 ISSN: 2715-0186 
dan alasannya akan didasarkan pada penerimaan dan definisi dari pola pikir yang melahirkan pengetahuan tersebut tanpa terekspos ketelitian dalam hal ketidakteraturan-keteraturan nilai-nilai incumbent itu sendiri. Pengetahuan terapan akan dihasilkan oleh orang lain.

- Seiring berjalannya waktu, hal ini tidak hanya akan menyamakan penyebab dan solusi masalah untuk setiap negara dan masyarakat, tetapi juga akan menyamakan keragaman masalah dan kemungkinan masalah yang dapat terwujud di semua masyarakat dan negara sekarang akan menjadi sama.

- Pada tahap ketiga ketika kemungkinan masalah dan alasan-hasil-solusi dari masalah tersebut telah menjadi sama, langkah-langkah yang akan diambil dan dihasilkan serta kebijakan yang diterapkan untuk mencegah masalah tersebut akan menjadi sama. Kebijakan dan perencanaan yang sama untuk setiap masyarakat dan negara bagian akan menjadi persyaratan, bukan permintaan.

- Terakhir, kebijakan yang diperlukan sejak awal dan penerapan kebijakan tersebut akan ditransformasikan menjadi keinginan dan tujuan masyarakat atau negara. Pencapaian suatu tujuan yang diyakini perlu, tentunya akan diinginkan dan menjadi tujuan / tujuan.

Pengetahuan eselon bawah yang merupakan eselon atas Dunia Islam perlu berkualitas untuk mempertahankan eselon atas ini dan menyelesaikan setiap masalah yang mungkin terwujud dalam terang tujuan ini serta memungkinkan prediksi apakah elemen struktural dan dasar pekerjaan yang terutama ingin mereka lindungi harus dilindungi dalam keadaan mereka saat ini atau apakah modifikasi diperlukan dan untuk JURNAL PAPATUNG: Vol. 2 No. 1 Tahun 2019 ISSN: 2715-0186 
dapat memprediksi masalah apa yang mungkin dihadapi dan untuk mengambil tindakan pencegahan untuk efek tersebut. Namun, jika informasi yang akan ditentukan sebelum menyelesaikan masalah tidak diperiksa kebenarannya, definisi dan diagnosis yang salah akan dihasilkan, yang akan membuat solusi tidak mungkin, dan bahkan berujung pada kemacetan.

\section{Untuk Menghilangkan Pengetahuan yang Salah, Penting untuk:}

- Mengajar dan mempelajari informasi yang berkaitan dengan dunia Islam secara keseluruhan, khususnya sejarah bagi semua pihak terkait

- Sadarilah bahwa informasi yang dihasilkan oleh orang lain yang benar dari segi mereka tidak benar untuk Dunia Islam

- Menghilangkan hambatan-hambatan yang menghalangi dunia dan Dunia Islam untuk mengenal diri mereka sendiri sebagai akibat dari penggambaran karakteristik Muslim secara berbeda dan menyembunyikan kebenaran di banyak bidang, terutama sejarah oleh kekuatan lain

- Koreksi informasi yang sengaja dimodifikasi

- Mengevaluasi kembali proses wajib dan idealnya disajikan seperti peradaban, modernisasi (westernisasi) dan globalisasi dari perspektif Dunia Islam

- Percaya bahwa budaya Islam perlu dilestarikan dalam hal mode, budaya populer (musik, seni, sastra, bioskop, dll.) Dalam kerangka ini dan pastikan bahwa upaya intensif dilakukan dalam hal ini.

JURNAL PAPATUNG: Vol. 2 No. 1 Tahun 2019

ISSN: 2715-0186 


\section{KESIMPULAN}

Ada tatanan yang memiliki sistem dan fungsi, tatanan yang diciptakan oleh Tuhan. Ada proses dalam pesanan ini yang tampaknya menyangkalnya namun berusaha untuk mengatasinya, sebuah sistem yang telah dibangun oleh manusia dan tidak memiliki urutan: Sistem Internasional Modern. Hakikat Islam adalah bertindak dengan cara yang tidak mengganggu berfungsinya sistem ciptaan Tuhan yang natural dan beretika. Sebenarnya kita tidak bisa berbicara tentang suatu masalah dalam sistem karena Dunia Islam yang didirikan oleh komunitas masyarakat yang bersatu di sekitar suatu masalah bersama sebenarnya bukanlah suatu sistem dengan fungsi dan strukturnya tetapi diartikan sebagai dunia, bukanlah nama sebuah sistem. Namun, dimungkinkan untuk berbicara tentang fungsi Sistem Internasional Modern, yang telah ditetapkan melalui ketidaktahuan dan kelalaian manusia sebagai alternatif untuk melawan tatanan Tuhan yang dimanifestasikan oleh esensi Islam dan terus menimbulkan penindasan dan masalah. Masalah atau masalah bukanlah masalah dunia Islam. Mereka adalah masalah Sistem Internasional Modern dan oleh karena itu masalah umat manusia. Satu-satunya solusi yang akan menyelamatkan umat manusia dari berfungsinya struktur / sistem saat ini yang terus-menerus menghasilkan / mewujudkan penindasan adalah banjir intelektual. Mentalitas yang akan meluncurkan bidang ini yang akan menegakkan / menjamin keadilan dan yang telah terstruktur dan mapan / diciptakan bagi umat manusia adalah tatanan yang berdasarkan Islam.

\section{DAFTAR PUSTAKA}

Thohir, A. (2009). Perkembangan Peradaban di Kawasan Dunia Islam (Vol. 1, No. 1). RajaGrafindo Persada.

JURNAL PAPATUNG: Vol. 2 No. 1 Tahun 2019

ISSN: 2715-0186 
Amin, S. H. (1989). Islamic Law \& Its Implications for Modern World. Royston.

Sunanto, M. (2007). Sejarah Islam Klasik: Perkembangan Ilmu Pengetahuan Islam.

Chambert-Loir, H., Guillot, C., \& Couteau, J. (2007). Ziarah dan Wali di Dunia Islam. Penerbit Serambi.

Ramdhani, R. (2018). Problematika Dakwah di Dunia Islam dan Solusi Filosofisnya. Jurnal Ilmiah Syi'ar, 13(2), 1-12.

Bakri, S. (2004). Islam dan Wacana Radikalisme Agama Kontemporer. Jurnal Dinika, 3(1), 1-8.

Muthahhari, M. (2009). Keadilan Ilahi: Asas Pandangan-Dunia Islam. Mizan Pustaka.

Rahardjo, M. D. (1987). Perspektif deklarasi Makkah: menuju ekonomi Islam. Mizan.

Mustika, D. (2011). Pencatatan Perkawinan dalam Undang-Undang Hukum Keluarga di Dunia Islam. INOVATIF| Jurnal Ilmu Hukum, 4(5).

Esposito, J. L. (1994). Ancaman Islam: mitos atau realitas?. Penerbit Mizan.

Ari, A. W. (2016). Syura dan demokrasi: Antara teori dan prakteknya dalam dunia islam. Jurnal Ilmu Agama: Mengkaji Doktrin, Pemikiran, dan Fenomena Agama, 17(2), 231-240.

Islam, D. (1982). Ilmu Pendidikan Islam. Jakarta: Proyeksi Pembinaan Perguruan Tinggi Agama/IAIN, 1983.

Santi, S. (2018). Relasi Agama dan Sains Menurut Seyyed Hossein Nasr dan Ian G Barbour. Prosiding Konferensi Integrasi Interkoneksi Islam Dan Sains, 1, 171-176.

Azra, A. (1994). Jaringan ulama: Timur Tengah dan kepulauan Nusantara abad XVII dan XVIII: melacak akar-akar pembaruan pemikiran Islam di Indonesia. Mizan.

Tabrani, Z. A. (2013). Modernisasi Pengembangan Pendidikan Islam (Suatu Telaah Epistemologi Pendidikan). Serambi Tarbawi, 1(1).

Shidiq, G. (2020). Teori maqashid al-Syari'ah dalam hukum Islam. Majalah Ilmiah Sultan Agung, 44(118), 117-130.

JURNAL PAPATUNG: Vol. 2 No. 1 Tahun 2019

ISSN: 2715-0186 